\title{
HIV-1 Frameshift RNA-Targeted Triazoles Inhibit Propagation of Replication-Competent and Multi-Drug-Resistant HIV in Human Cells
}

Thomas A. Hilimire, ${ }^{\dagger}$ Jeffrey M. Chamberlain, ${ }^{\S}$ Viktoriya Anokhina, ${ }^{\dagger}$ Ryan P. Bennett, ${ }^{*}$ Oliver Swart," Jason R. Myers, ${ }^{\perp} \odot$ John M. Ashton, ${ }^{\perp}$ Ryan A. Stewart, ${ }^{\#}$ Aaron L. Featherston, ${ }^{\ddagger}$ Kathleen Gates, ${ }^{\S}$ Eric D. Helms, ${ }^{\triangleright}$ Harold C. Smith, ${ }^{\dagger, \#}$ Stephen Dewhurst, ${ }^{\S}$ and Benjamin L. Miller ${ }^{*, \dagger}, \oplus$

${ }^{\dagger}$ Departments of Biochemistry and Biophysics, ${ }^{\ddagger}$ Dermatology, ${ }^{\S}$ Microbiology and Immunology, ${ }^{\|}$Chemistry, and ${ }^{\perp}$ Genomics Research Center, University of Rochester, Rochester, New York 14642, United States

\#OyaGen, Inc., Rochester, New York 14623, United States

$\nabla^{D}$ Department of Chemistry, SUNY Geneseo, Geneseo, New York 14454, United States

\section{Supporting Information}

ABSTRACT: The HIV-1 frameshift-stimulating (FSS) RNA, a regulatory RNA of critical importance in the virus' life cycle, has been posited as a novel target for anti-HIV drug development. We report the synthesis and evaluation of triazole-containing compounds able to bind the FSS with high affinity and selectivity. Readily accessible synthetically, these compounds are less toxic than previously reported olefin congeners. We show for the first time that FSS-targeting compounds have antiviral activity against replication-competent HIV in human cells, including a highly cytopathic, multidrug-resistant strain. These results support the viability of the HIV-1 FSS RNA as a therapeutic target and more generally highlight opportunities for synthetic molecule-mediated interference with protein recoding in a wide range of organisms.

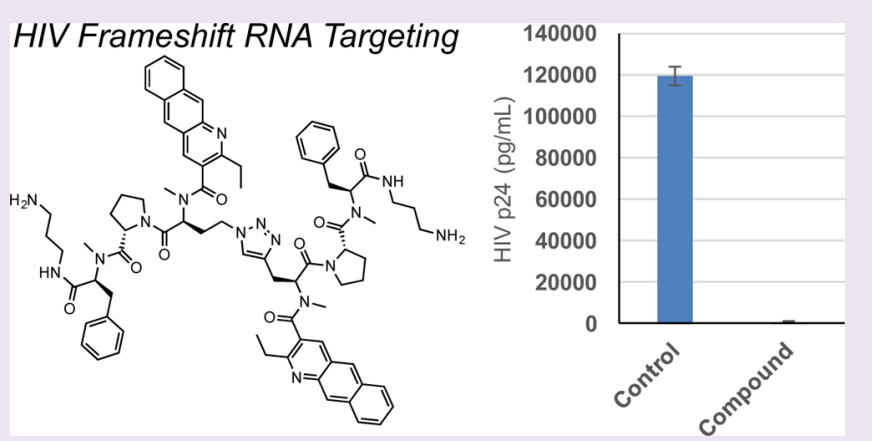

7 here is a rapidly expanding recognition that RNA is of high significance as a therapeutic target. ${ }^{1,2}$ In addition to the importance of coding regions of mRNA, noncoding RNA sequences (including miRNA, lncRNA, and others) and structured, regulatory regions of RNA found within coding sequences have been demonstrated to have critical roles in human health and disease. Recent work has revealed the utility of RNA-targeted compounds in the treatment of splicing diseases, ${ }^{3-8}$ and as candidate antibiotics via modulation of bacterial riboswitch activity. ${ }^{9}$ Finally, RNAs of potential therapeutic significance have also been identified in pathogenic agents, including viruses such as HIV, SARS, and HTLV. ${ }^{10}$

One RNA sequence that is particularly attractive both as a model system for fundamental studies of RNA-targeted compound design and as a potential drug target is a highly stable RNA hairpin that serves as a regulatory element in the translation of Gag and Gag-Pol polyproteins in HIV-1. ${ }^{11,12}$ Specifically, the mRNA encoding these proteins carries a stop codon at the end of the gag gene. In a significant majority of cases (90-95\%), the ribosome reads to the end of the gag reading frame, reaches this stop codon, and produces only Gag, a polyprotein that is further processed to yield HIV-1 structural proteins. However, in approximately $5-10 \%$ of all gag-pol mRNA translation events, interaction of the ribosome with a particular stemloop within the gag-pol transcript (the HIV-1 Frameshift Stimulating Stemloop, or HIV-1 FSS RNA) causes it to slip back one nucleotide on an upstream U-rich "slippery sequence" (Figure 1). When the ribosome resumes the process

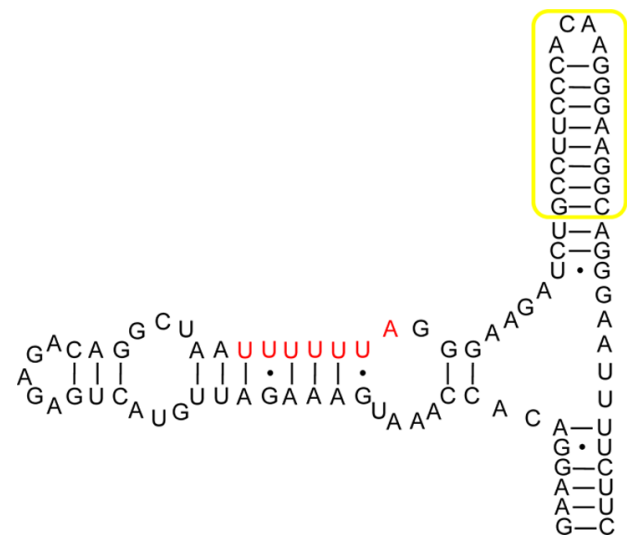

Figure 1. Primary and secondary structure of the HIV-1 frameshift element (group M clade D sequence), based on SHAPE data. ${ }^{25}$ The slippery sequence is indicated in red, and the frameshift-stimulating stemloop (FSS) employed in these studies is highlighted with a yellow box.

Received: January 19, 2017

Accepted: April 27, 2017

Published: April 27, 2017 


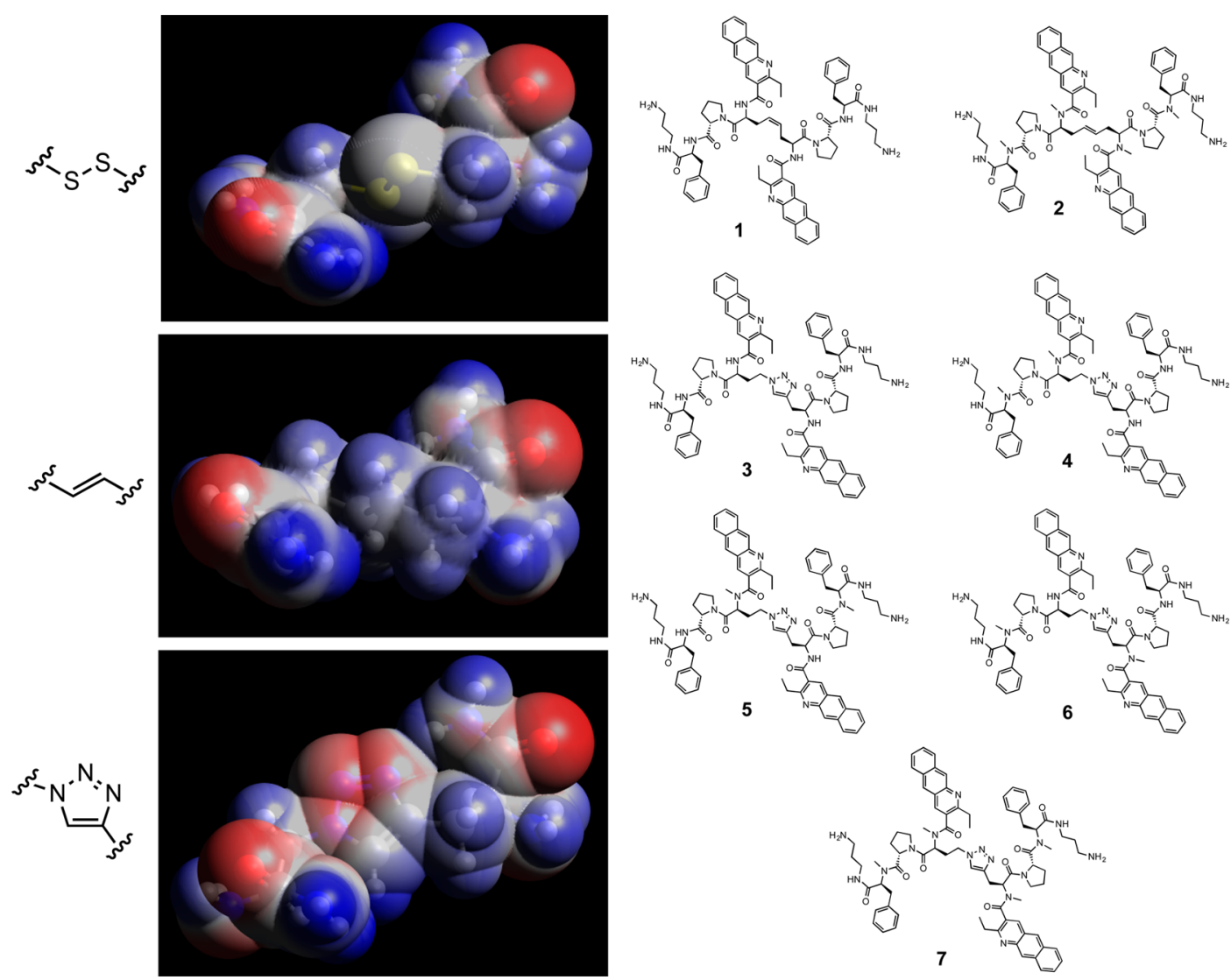

Figure 2. Left: Comparison of side-chain bridged dipeptides linked by disulfide (top), olefin (middle), or 1,4-triazole (bottom). Surfaces are colored by electrostatic potential. Right: Chemical structure of compounds 1-7.

of translation, it does so in a new reading frame (a -1 ribosomal frameshift $\left.{ }^{13}\right)$. As such, it no longer recognizes the gag stop codon and instead continues to process the mRNA until full-length Gag-Pol is produced. Pol consists of vital enzymes of HIV-1 including HIV protease, reverse transcriptase, and integrase. It is absolutely required for the production of infectious virons. Although a detailed mechanism of frameshifting remains elusive, the high conservation of the FSS RNA sequence in HIV-1 isolates ${ }^{14}$ combined with experimental work demonstrating changes in frameshifting frequency as a function of mutations to this RNA ${ }^{15,16}$ suggest that its presence and structure are critical. Alterations in the Gag:Gag-Pol ratio in either direction have been found to substantially reduce the infectivity of product virions. Thus, compounds able to bind this RNA and influence frameshifting have been posited as a new class of anti-HIV agents. ${ }^{11,12}$

To address the general problem of identifying selective binders for biomedically relevant RNA targets, we have developed a discovery protocol based on initial rapid identification of hit molecules using Resin-Bound Dynamic Combinatorial Chemistry (RBDCC) $)^{17,18}$ followed by an iterative medicinal chemistry approach to affinity maturation. As part of this process, it is necessary to convert the disulfide moiety used as a "mutatable" group in RBDCC to a nonreducible functional group suitable for further studies in a biological context. Thus far, we have focused on the use of olefins as disulfide isosteres (or, more appropriately, "bioisosteres" 19 since the geometry is by no means identical). This strategy has resulted in compounds with relevant activity in vitro and in vivo, including compounds targeting the HIV-1
FSS. $^{20-22}$ Our prior efforts toward enhancing the affinity and selectivity of HIV-1 FSS-targeted compounds via directed analog synthesis culminated in the recent disclosure of a series of $N$-methyl amides with exceptionally high affinity to and selectivity for the FSS RNA. ${ }^{22}$ Compound 2, for example (Figure 2), was found to have a dissociation constant $\left(K_{D}\right)$ for the FSS RNA of $13.0 \pm 5.0 \mathrm{nM}$ via surface plasmon resonance, approximately 5 -fold tighter binding than 1. Compound 2 was also found to inhibit HIV infectivity in a pseudotyped (singlecycle) HIV assay. We have also successfully employed this approach to address a sequence of relevance to triplet repeatmediated splicing disease (Myotonic Dystrophy Type 1, DM1), ${ }^{23}$ yielding compounds with activity in a DM1 mouse model. $^{24}$

While the affinities and activities of RNA-binding compounds we have synthesized to date incorporating an olefin bioisostere have been encouraging, we sought an alternative disulfide replacement that would permit simpler and more readily scalable synthesis. To that end, the 1,4-triazole substructure seemed particularly attractive, given the highly robust metal-catalyzed Huisgen cycloaddition conditions that have been developed for its synthesis. ${ }^{26,27}$ Despite the immense body of literature on the use of triazoles in chemistry, including in peptidomimetics, ${ }^{28,29}$ and in RNA-binding compounds, ${ }^{30-32}$ there are relatively few examples of this substructure serving as a bioisosteric replacement for a disulfide. In addition to its first reported use in 2004, ${ }^{33}$ Suga and colleagues successfully employed intramolecular triazole formation as a disulfide replacement in the context of bicyclic peptides, ${ }^{34}$ and a ruthenium-catalyzed cyclization strategy has been described by 
the Kolmar group for the synthesis of 1,5-disubstituted triazole analogs of cyclic disulfide-containing trypsin inhibitors. ${ }^{35}$ In the latter case, inhibitory activity of the triazole peptidomimetic was found to be similar to that of the parent disulfide. Subtle differences between the native disulfide and isosteric triazole have also been reported to have a negative effect on biological activity, however, causing unfolding of insulin glargine analogs. ${ }^{36}$

The structural similarities of 1,4-disubsituted triazoles, disubstituted olefins, and disulfides are readily apparent from DFT calculations (Figure 2); however, differences are also obvious. With its calculated local minimum $86.6^{\circ}$ torsional angle, consistent with the well-established reference value of $90^{\circ}$ for L-cystine, ${ }^{37}$ the disulfide bond torsional landscape is quite different from either the olefin or triazole. The distance between flanking alpha carbons is most similar for the trans olefin (5.77 $\AA$ vs $5.74 \AA$ for the disulfide). This distance is slightly shorter for the cis olefin $(5.32 \AA)$, and over an Ångstrom longer for the triazole $(6.94 \AA)$. Electrostatic potential surfaces are also quite different for the three substructures, with the triazole presenting the most overall negatively charged surface. Nonetheless, pendant functionality is capable of being positioned in a similar orientation, and thus we anticipated that the 1,4-triazole would be a suitable disulfide and olefin substitute in HIV-1 FSS binding compounds.

\section{RESULTS AND DISCUSSION}

Peptide precursors to compounds 3-7 were synthesized in the solid phase using methods analogous to our previously reported results. ${ }^{20-22}$ Synthesis of 1,4-triazole analogs also provided us with the first opportunity to synthesize and test nonsymmetrical $N$-methylation patterns (e.g., compounds 4, 5, and 6), as previous attempts to accomplish this using on-bead olefin cross-metathesis had met with modest yields, at best. The $\mathrm{Cu}(\mathrm{I})$-catalyzed Huisgen cycloaddition was conducted on resin using methodology described by Meldal and co-workers. ${ }^{38}$ In each case, this method provided the desired compound following cleavage from the resin and concomitant deprotection as a single major peak by analytical HPLC.

In previous work, we have monitored binding-dependent quenching of benzo[g]quinoline fluorescence to determine dissociation constants. $^{21,22}$ Unfortunately, initial attempts to measure the affinity of triazole-containing compounds for the HIV-1 FSS RNA by fluorescence titration were unsuccessful due to irreversible photobleaching of the compounds. Therefore, we measured binding constants by surface plasmon resonance (SPR; Table 1). In this assay, RNA is immobilized on the SPR chip while the compound is flowed through in solution. This allows for determination of kinetic rate constants of binding as well as thermodynamic parameters. ${ }^{39} \mathrm{~A}$ comparison of the measured affinities for $\mathbf{1}$ and $\mathbf{3}$ indicates that substitution of triazole for olefin has no effect on affinity (within error). $\mathrm{N}$-methylation of $\mathbf{3}$ had only a modest effect on affinity; compound 7 displayed the highest affinity with a binding constant 6-fold tighter than 3. As with previously described $N$-methyl amide analogs such as 2 , affinity enhancements are largely driven by an increase in on-rate $\left(k_{\mathrm{a}}\right)$. This is consistent with the hypothesis that $N$-methylation reduces the complexity of the ground state conformational ensemble and favors a conformer or conformers able to bind the RNA, and with the known propensity of $\mathrm{N}$-methylation to alter peptide conformation. ${ }^{40}$ In order to test selectivity, SPR measurements were made using a competitive assay, in which a mixture of the
Table 1. Binding Affinities and Kinetics for Compounds 1-7 Binding the HIV-1 FSS RNA As Measured by SPR

\begin{tabular}{|c|c|c|c|c|}
\hline compound & $k_{\mathrm{a}}\left(1 / \mathrm{M}^{*} \mathrm{~s}\right)$ & $k_{\mathrm{d}}(1 / \mathrm{s})$ & $K_{\mathrm{D}}(\mathrm{nM})$ & $\begin{array}{l}K_{\mathrm{D}} \text { in the presence of } \\
5 \times \text { tRNA (nM) }\end{array}$ \\
\hline $1^{a}$ & $\begin{array}{l}(2.2 \pm 0.8) \\
\times 10^{4}\end{array}$ & $\begin{array}{l}(1.4 \pm 0.1) \\
\times 10^{-3}\end{array}$ & 71 & ND \\
\hline $2^{b}$ & $\begin{array}{l}(1.6 \pm 0.7) \\
\times 10^{5}\end{array}$ & $\begin{array}{l}(1.9 \pm 0.5) \\
\times 10^{-3}\end{array}$ & $13 \pm 5$ & ND \\
\hline 3 & $\begin{array}{l}(8.8 \pm 3) \times \\
10^{4}\end{array}$ & $\left(\begin{array}{l}6.8 \pm 1) \times \\
10^{-3}\end{array}\right.$ & $97 \pm 20$ & $32 \pm 6$ \\
\hline 4 & $\begin{array}{c}(5.3 \pm 2) \times \\
10^{4}\end{array}$ & $\begin{array}{c}(3.3 \pm 1) \times \\
10^{-3}\end{array}$ & $68 \pm 7$ & $62 \pm 20$ \\
\hline 5 & $\begin{array}{l}(1.2 \pm 0.3) \\
\times 10^{5}\end{array}$ & $\begin{array}{l}(6.2 \pm 0.4) \\
\times 10^{-3}\end{array}$ & $59 \pm 10$ & $31 \pm 5$ \\
\hline 6 & $\begin{array}{l}(1.5 \pm 0.4) \\
\times 10^{5}\end{array}$ & $\begin{array}{l}(4.6 \pm 0.4) \\
\times 10^{-3}\end{array}$ & $41 \pm 10$ & $91 \pm 5$ \\
\hline 7 & $\begin{array}{l}(1.9 \pm 0.3) \\
\times 10^{5}\end{array}$ & $\begin{array}{l}(3.0 \pm 0.5) \\
\times 10^{-3}\end{array}$ & $16 \pm 4$ & $130 \pm 20$ \\
\hline
\end{tabular}

${ }^{a}$ Values previously reported in ref $21 .{ }^{b}$ Values previously reported in ref 22. Error is derived as the standard deviation from the mean of the averaged individual fits.

compound plus a 5-fold excess of yeast tRNA (relative to compound concentration) in solution was flowed over the SPR chip. Of course, this constitutes an even larger excess of tRNA over the amount of HIV-1 FSS RNA immobilized on the sensor chip, and as such represents a stringent assay. We observed that, of the compounds tested, only 7 showed a significant change in $K_{D}$ in the presence of tRNA.

Cellular permeability and toxicity were assessed in HEK293T cells. Toxicity was first examined via WST-1 assay. ${ }^{41}$ All triazole-containing compounds were significantly less toxic than previously reported compounds (Figure 3; previous data for 2 are shown for reference). Compound $\mathbf{5}$ in particular was essentially nontoxic up to the highest examined concentration of $110 \mu \mathrm{M}$. Although previous experiments have produced clustering of toxicity among closely related analogs binding the HIV-1 FSS, triazole-containing compounds were found to have

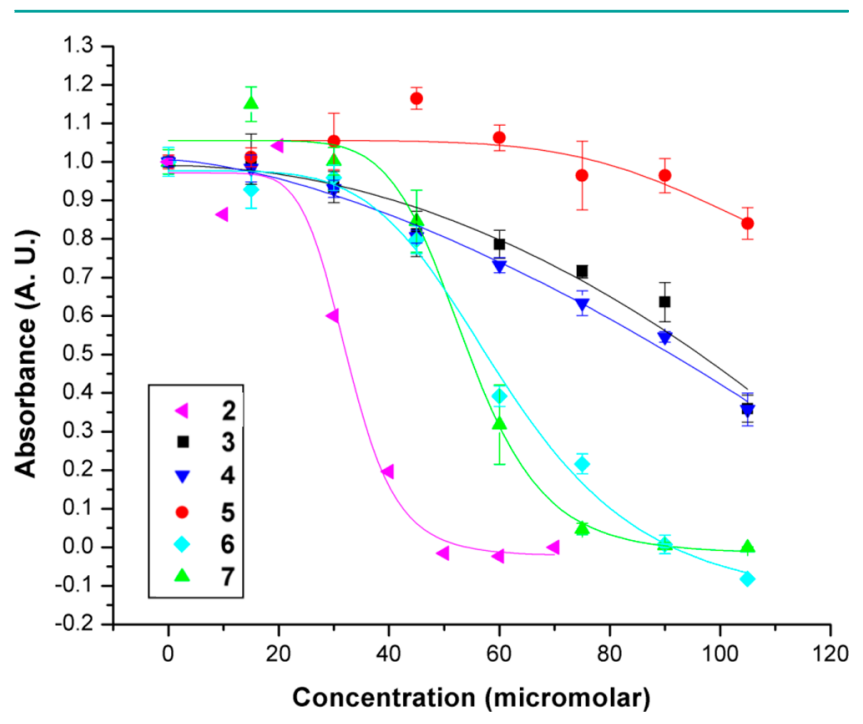

Figure 3. Reduced toxicity relative to $\mathbf{2}$ in HEK293T cells exhibited by triazole analogs as measured by WST-1 assay. Data for compound $\mathbf{2}$ is from ref 22 and has been normalized to the absorbance range observed for compounds 3-7. Lines represent logistic fits of the data for each compound. The assay was run in triplicate; reported error is the standard deviation from the mean for each condition. 
a spread of toxicities. Differences between compounds 5 and $\mathbf{6}$ were particularly unexpected as these compounds are chemically similar; while compound 5 has a toxic dose, $\mathrm{TD}_{50}$, of $\geq 110$ $\mu \mathrm{M}$, compound 6 was found to be roughly twice as toxic $\left(\mathrm{TD}_{50}\right.$ $=60 \mu \mathrm{M}$ ). Flow cytometry revealed that the permeability of triazole analogs largely followed their methylation pattern, with tetra- $N$-methyl compound 7 displaying the greatest cell permeability, and the non- $N$-methylated compound 3 the least (Supporting Information). These results are consistent with trends previously observed for compounds 1 (unmethylated olefin) and $\mathbf{2}$ (tetramethylated olefin), which are provided in the figure for reference.

We further evaluated compound selectivity by examining the effect of $0,6.83$, and $20 \mu \mathrm{M}$ concentrations of compound 7 on HEK293T cells by RNaseq. A total of 17872 transcripts were analyzed for each condition. The set of significantly altered genes relative to control ( $0 \mu \mathrm{M}$ compound) for the two concentrations was compared using the Web tool InteractiVenn. ${ }^{42}$ One of the $6.83 \mu \mathrm{M}$-treated samples behaved as an outlier, and therefore the analysis was conducted both with and without considering this sample. Disregarding the outlier sample revealed 53 transcripts with a statistically significant change in both the 6.8 and $20 \mu \mathrm{M}$ compound-treated conditions (Figure 4). Of these, only two showed a greater than 2-fold change (considered biologically significant ${ }^{4}$ ) in both sets: Genbank IDs RWDD4P2 and ElF4A1P2, both pseudogenes. Inclusion of the outlier sample in the analysis resulted in only a subset (13) of these transcripts called differentially expressed. Therefore, although we cannot a priori conclude that inclusion of the outlier is not biologically relevant, its exclusion produces the most conservative estimate of compound 7's effect on HEK293T cells. The $20 \mu \mathrm{M}$-treated samples showed a few additional transcripts with significant changes. These included the expressed genes early growth response 1 $\left(\right.$ EGR1; $\log _{2}($ fold change $\left.)=1.69\right)$, microtubule associated protein 1 light chain 3 beta 2 (MAP1LC3B2; $\log _{2}$ (fold change) = 5.56), phosphatidylinositol 4-kinase type 2 beta (PI4KIIB; $\log _{2}($ fold change $\left.)=-1.66\right)$, and ubiquitin specific peptidase 41 (USP41; $\log _{2}$ (fold change $=-7.85$ ). While the tested concentration is lower than that at which changes in WST-1 metabolism indicative of toxicity were observed (vide supra) for compound 7, these additional changes may reflect compounddependent increases in cell stress and will be examined further. Overall, however, the low number of significantly altered transcripts, and in particular the near absence of expressed genes altered, highlights the selectivity of compound 7 despite its status as the least-selective of the triazole analogs studied, based on tRNA competition SPR.

We next examined the effect of triazole-containing FSS RNA binders on pseudotyped HIV virion production and infectivity. In this system, ${ }^{43}$ HEK293T producer cells are first transfected with a proviral HIV plasmid modified such that the env gene is deleted, and the nef gene is replaced with green fluorescent protein (GFP) to assist with virion detection and quantitation. Cotransfection of a vesicular stomatitis virus type G (VSV-G) plasmid provides the envelope functionality in trans to enable production of single-cycle infectious virions. Visualizing GFP production through fluorescence microscopy also allows for a qualitative assessment of virion production in producer cells. Virions produced after a 24-h incubation with various concentrations of compounds were harvested and used to infect TZM-bl reporter cells with virion quantities first normalized via a p24 ELISA assay. TZM-bl cells express

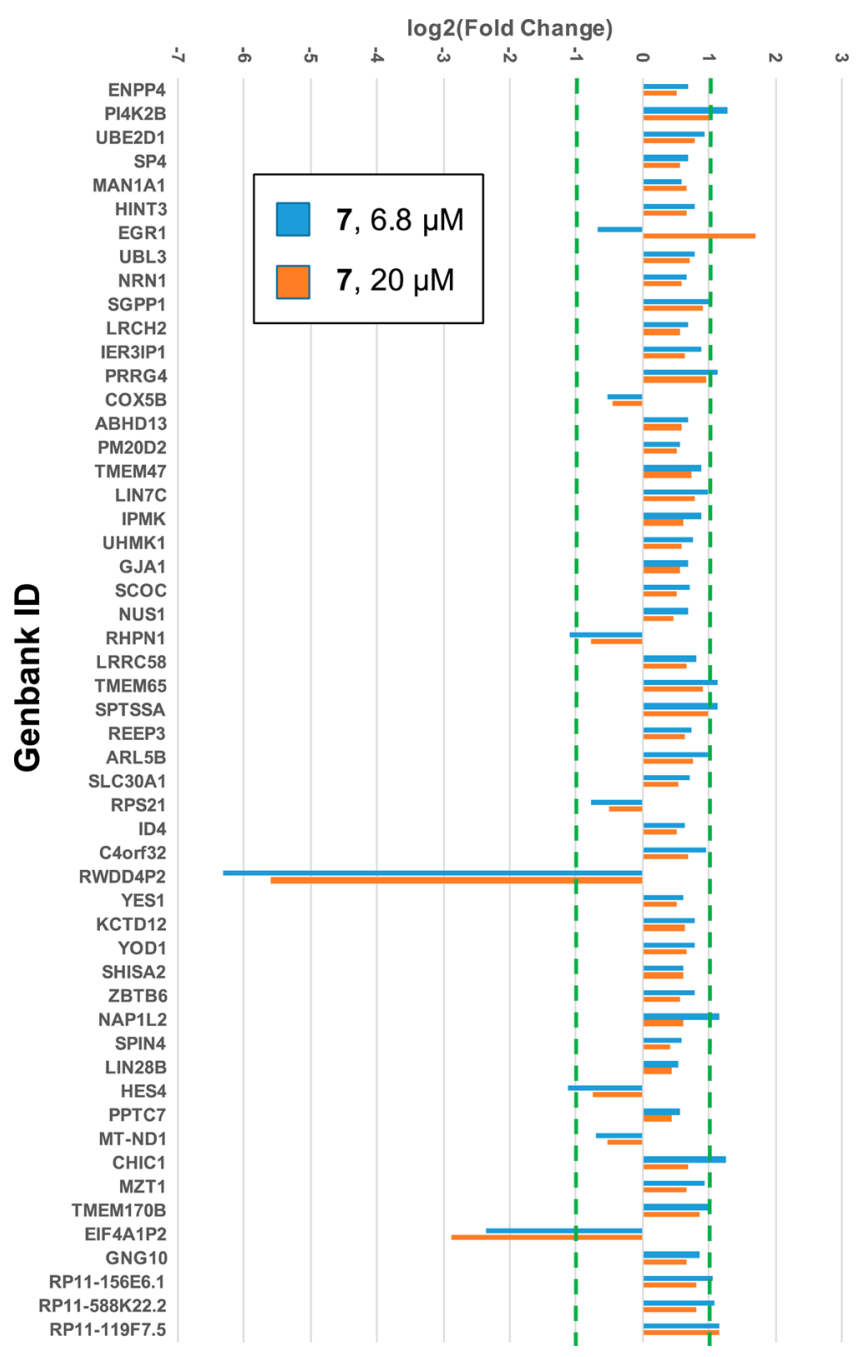

Figure 4. RNAseq data for compound 7 in HEK293T cells revealing 53 transcripts altered with statistical significance in both 6.8- and 20$\mu \mathrm{M}$-treated sets of samples. Of these, only RWDD4P2 and ElF4A1P2, both pseudogenes, show consistent changes $>2$-fold $\left(\log _{2}(n)= \pm 1\right)$. This assay was run in triplicate.

luciferase upon infection with $\mathrm{HIV}^{44}$ (via the HIV LTR promoter), providing a quantitative readout of infectivity. Indinavir, an FDA-approved protease inhibitor, ${ }^{45}$ was employed as a positive control. We observed that compounds 3-7 substantially decreased virion production in a concentration dependent manner, as evidenced by a decrease in GFP fluorescence (Supporting Information). Virions produced were less infectious, and infectivity decreased strongly with increasing concentration of the compound (Figure 5a). New compounds were slightly less effective than previously reported compound 2; this is offset by their significantly lower toxicity.

Western blots were used to assess the effect of FSS-binding compounds on the Gag/Gag-Pol ratio. Using a p24 antibody as a probe, all new compounds were found to increase the amount of Gag-Pol relative to Gag, with 5, 6, and 7 having the strongest effect (Figure $5 b$ ). We also examined lysates from compoundtreated producer cells by Western blot. No significant changes in Gag/Gag-Pol ratios were observed relative to control, suggesting that most of the excess Gag-Pol and its products are packaged into virions (Supporting Information).

To confirm the activity of compounds in a replicationcompetent virus, we examined the effect of compounds 2, 3, 
a)

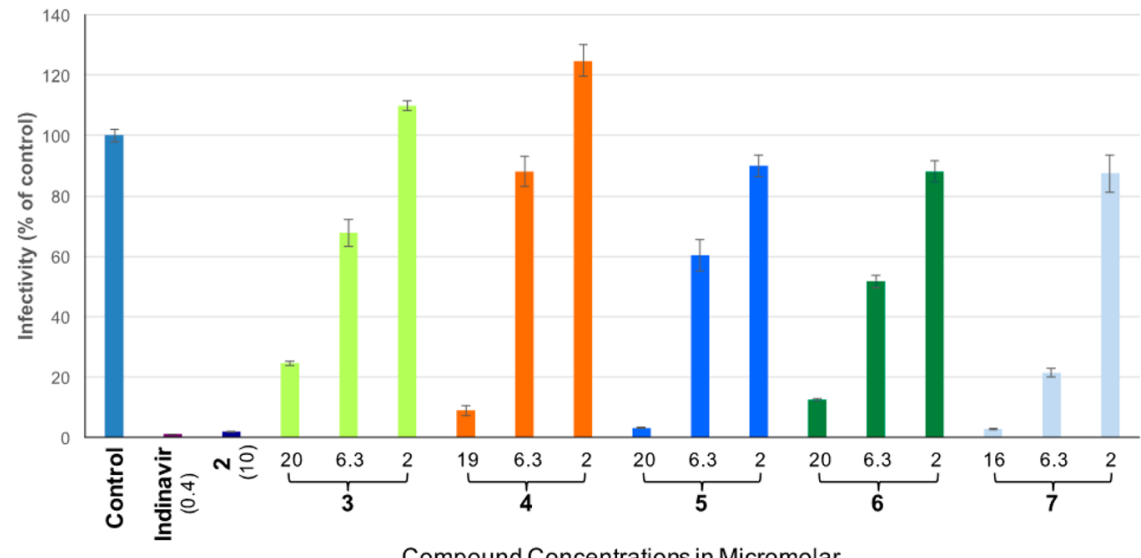

b)

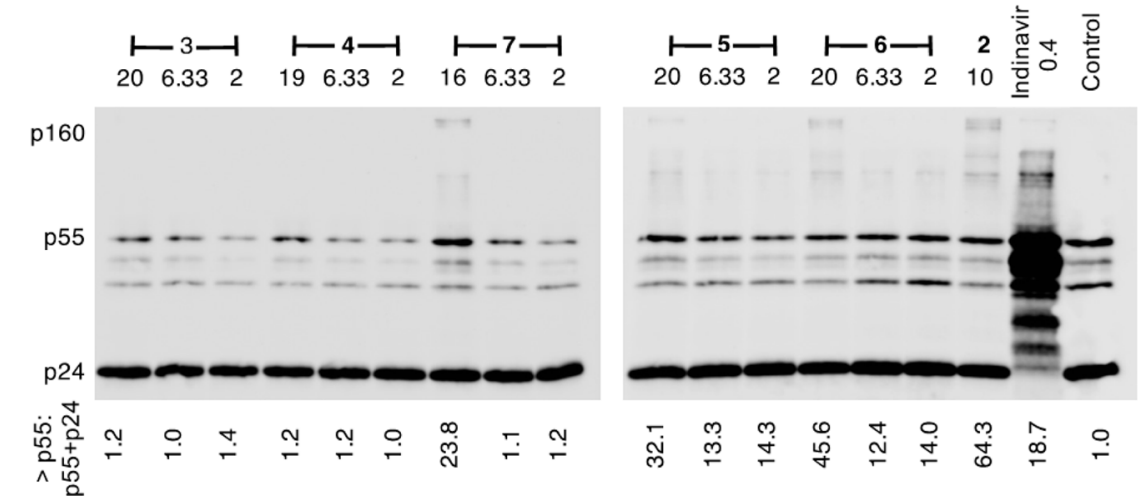

Figure 5. (a) Infectivity of pseudotyped HIV-1 reduced by triazoles 3-7. Error represents the standard deviation on the mean; each condition was run in triplicate. (b) Compounds induce production of pseudotyped HIV virions with altered Gag/Gag-Pol ratios, consistent with increased frameshifting. Western blots were probed with an anti-p24 antibody; all bands above p55 (Gag) are presumed to be processed from p160 (Gag-Pol).
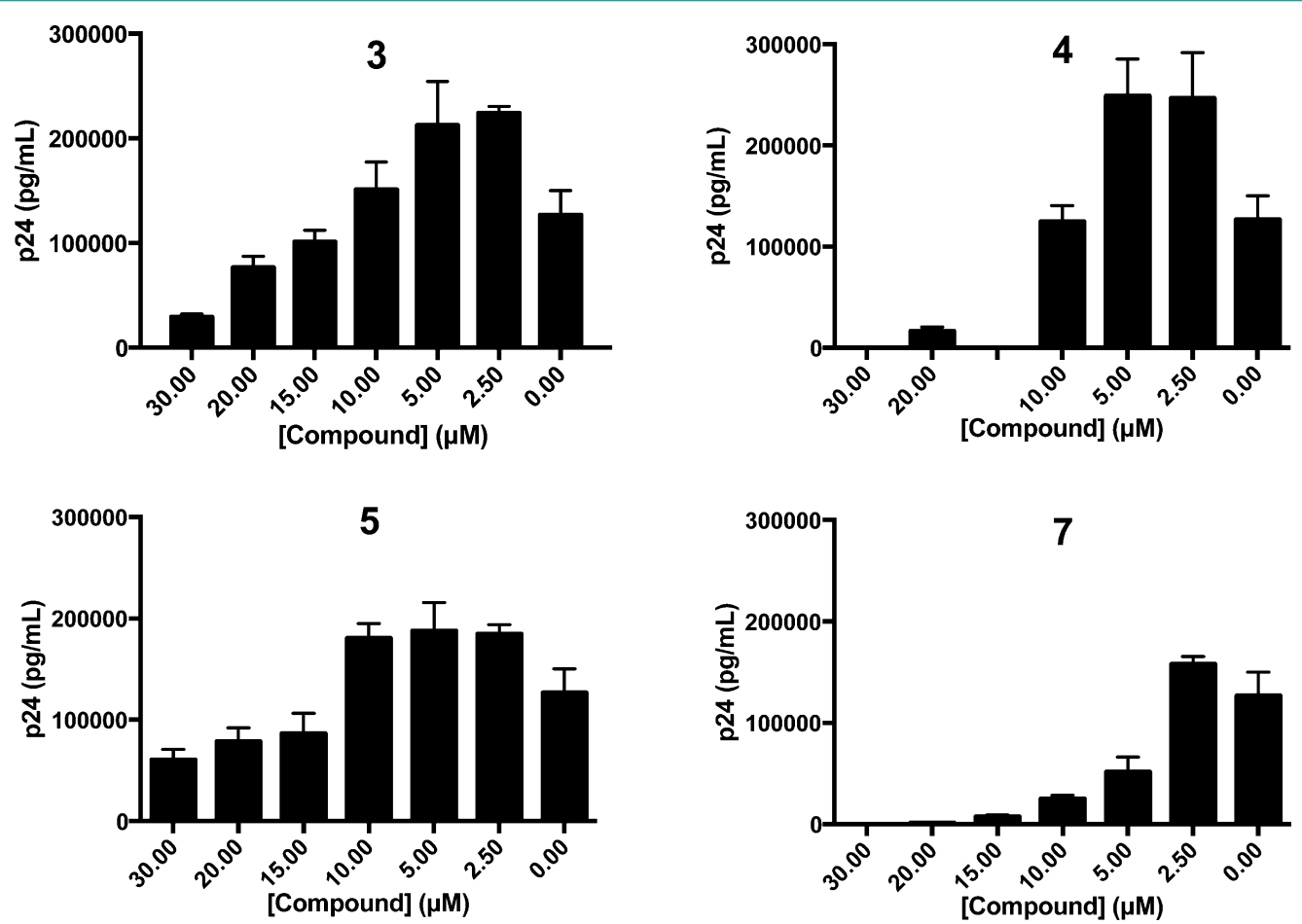

Figure 6. Production of infectious HIV-1 IIIB in MT-2 cells inhibited by HIV-1 FSS-targeted compounds. All concentrations ( $x$ axis) in $\mu$ M; HIV was quantified by p24 ELISA assay ( $y$ axis). No $15 \mu \mathrm{M}$ concentration was tested for compound 4. Error represents the standard deviation on the mean; each condition was run in triplicate.

and 7 on propagation of $\mathrm{HIV}_{\mathrm{IIIB}}$, a common laboratory strain, $^{46-48}$ in the human MT-2, ${ }^{49,50}$ T-cell line. Cells were first infected with the virus for $8 \mathrm{~h}$ in the absence of the compound, then spun down and resuspended in fresh media. 

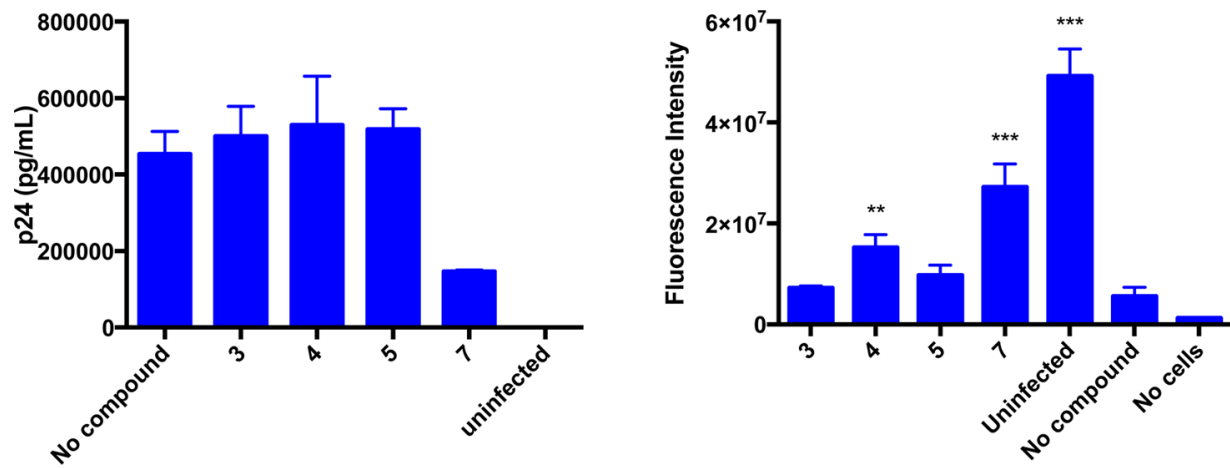

Figure 7. Multidrug-resistant HIV strain HIV-1 AD.MDR01 at a concentration of $15 \mu \mathrm{M}$ (left) inhibited by compound 7. Right: both compounds 7 and 4 provide statistically significant improvement in survival of multidrug-resistant infected MT-2 cells (right; asterisks indicate statistical significance vs no compound control, as determined by one-way ANOVA with pairwise posthoc Dunnett's multiple comparisons test). Data acquired at day 6 postinfection. Error represents the standard deviation on the mean; each condition was run in triplicate.

Varying concentrations of compounds were added, with each condition tested in triplicate. In preliminary experiments with compounds 2,3 , and 7 , one-half of the medium was harvested at 2 days postinfection and replaced with an equivalent volume of medium \pm compound. The medium removed was examined for viral particles using a p24 ELISA assay. This procedure was repeated at days 4 and 6 postinfection. These experiments revealed a dose- and time-dependent inhibition of $\mathrm{HIV}_{\text {IIIB }}$ for all three compounds (Supporting Information), with very low (compound 3) or undetectable (compounds 5 and 7) levels of virus present for the highest doses at days 4 and 6 postinfection. Subsequently, full dose-response profiles were obtained for compounds $3,4,5$, and 7 , at 6 days postinfection (Figure 6). $\mathrm{IC}_{50}$ values were obtained via four-parameter logistic fits of these data. They indicate similar potencies for 3, 4, and 5 (15.33, 10.17, and $14.23 \mu \mathrm{M}$, respectively), and a somewhat higher potency for compound $7(4.86 \mu \mathrm{M})$. Decreases in virus were not due to inhibition of cell growth; indeed, more cells were present in the compound-treated wells than in the untreated but virus-infected wells at day 6 (Supporting Information), as measured by Alamar blue assay. This effect is striking and consistent with compound-mediated protection from virus-induced apoptosis. Such an effect has been seen with other anti-HIV agents. ${ }^{51}$ Compound 7 proved toxic to HIVinfected MT-2 cells at concentrations above $15 \mu \mathrm{M}$.

Because FSS-targeted compounds inhibit HIV-1 via a different mechanism than existing antivirals, we also examined the ability of 3, 4, 5, and 7 to inhibit a multidrug-resistant strain of the virus. The patient-derived strain HIV-1 AD.MDR01 is resistant to a broad range of protease inhibitors, nucleoside reverse transcriptase inhibitors, and nonnucleoside reverse transcriptase inhibitors. It is also highly cytopathic. ${ }^{52,53}$ Using a similar protocol to that employed for the $\mathrm{HIV}_{\mathrm{IIIB}}$ experiments detailed above, HIV-1 AD.MDR01 infected human MT-2 cells were treated with $15 \mu \mathrm{M}$ doses of $3,4,5$, and 7 and evaluated both for production of the virus (p24 ELISA) and cell survival (Alamar blue) at 6 days postinfection. We were gratified to observe that compound 7 inhibited this strain, and both 4 and 7 provided statistically significant protection against its cytopathic effect (Figure 7).

There is a continuing need to develop new anti-HIV therapies, and particularly to explore novel therapeutic targets. ${ }^{54}$ The HIV frameshift has been recognized for some time as an attractive potential avenue to viral inhibition, but previously the lack of effective strategies for sequence-selective
RNA recognition has made addressing this target a challenge. Our past work demonstrated the feasibility of degrading the infectivity of pseudotyped HIV via FSS RNA-targeted compounds. Here, we demonstrate for the first time that this strategy can also yield compounds able to strongly inhibit replication of a laboratory strain of HIV in human T cells, and one compound inhibits a highly cytopathic, multidrug-resistant strain. This is a critical step in the validation of the HIV-1 FSS RNA as a therapeutic target. It is also important to note that frameshifting is not limited to HIV-1. It is widely used in many pathogenic viruses (for example, the SARS coronavirus ${ }^{55,56}$ and HTLV- ${ }^{57}$ ) and also in eukaryotes, including humans. ${ }^{58,13,59}$ These recoding processes are all possible control points for driving therapeutic outcomes. As such, the approach we have applied to frameshifting in HIV-1 should be extendable to synthetic molecule control over a broad range of recoding events. In the broader context of RNA recognition, this work also demonstrates that the use of 1,4-disubsituted triazoles as disulfide bioisosteres is effective.

\section{METHODS}

Density Functional Theory (DFT) Calculations. Structures depicted in Figure 2 were minimized with GAMESS $^{60}$ version 1 May 2013 (R1) using the B3LYP ${ }^{61}$ density functional method and the 6$3 \lg (\mathrm{d})$ basis set. van der Waals surfaces colored by electrostatic potential were visualized with Avogadro 1.1.1.

Synthesis of Compounds 3-7. Compounds were synthesized using standard solid phase peptide protocols. Wang Resin (0.22 $\mathrm{mmol} /$ gram for alkyne containing monomers, $0.68 \mathrm{mmol} / \mathrm{gram}$ for azide containing monomers) was activated with carbonyl diimidazole (CDI, 10 equiv) in dimethylformamide (DMF) for $4 \mathrm{~h}$ followed by treatment with 1,3-diaminopropane (10 equiv) in DMF for $4 \mathrm{~h}$. Amino acids were coupled using 3.1 equiv of Fmoc-AA-OH, where AA is Phe, Pro, Pra, Aha, or N-Me-Phe; 2.9 equiv of HATU, and 5 equiv of DIPEA in DMF for $2 \mathrm{~h}$. Deprotection of Fmoc was accomplished using 20\% piperidine in DMF for $1 \mathrm{~h}$. Where N-Me amino acids were needed that were not commercially available, Fmoc was first removed using standard methods followed by treatment of the resin with 3 equiv of 2-nitrobenzenesulfonyl chloride (NOSYL-Cl) and 5 equiv of collidine in DCM for $2 \mathrm{~h}$. This activated resin was then treated with 8 $\mathrm{mL}$ of TMS-diazomethane and $0.5 \mathrm{~mL}$ of methanol in DCM overnight. Methylation was monitored by HPLC. To remove the NOSYL group, resin was treated with 3 equiv of 2-mercaptoethanol and 5 equiv of DBU for $1 \mathrm{~h}^{62}$ The end of each monomer was capped with benzo[g]quinoline. To form the 1,4 substituted triazole ring, the azide-containing peptide was cleaved with $98 \%$ trifuoroacetic acid (TFA), 1\% triethyl silane (TES), and $1 \%$ water, and ether was precipitated to yield a crude yellow solid that was used without further 
purification. Next, the resin-bound alkyne was dried under a vacuum, and washed three times with dry THF. CuI (2 equiv) and DIPEA (50 equiv) were added to the vessel in anhydrous THF. After mixing for 15 min, azide ( 2 equiv based on resin loading) was added, and the resulting green/brown solution mixed overnight. The resin was then washed three times with THF, three times with DCM, three times with DMF, and three times with DCM, then cleaved with 98\% TFA, $1 \%$ TES, and $1 \%$ water for $2 \mathrm{~h}$ followed by rotary evaporation and ether precipitation.

Surface Plasmon Resonance. SPR was conducted using a Biacore X (Biacore, Inc.) instrument. Streptavidin was immobilized to $7500 \mathrm{RU}$ in both flow cells using EDC/NHS coupling to a CM5 chip (GE). The surface was then blocked with ethanolamine. Next, $50 \mu \mathrm{M}$ 5 -biotin HIV-1 FSS (obtained as an HPLC-purified sample from Integrated DNA Technologies, Inc.) was refolded in $10 \mathrm{mM}$ HEPES and $150 \mathrm{mM} \mathrm{NaCl}$ at $\mathrm{pH} 7.4$ by heating at $98{ }^{\circ} \mathrm{C}$ in a heater block for 2 min then cooled to RT and immobilized on one flow cell of the SPR chip to a density of $1100 \mathrm{RU}$. The control flow cell was then blocked with an injection of $50 \mu \mathrm{M}$ biotin in $10 \mathrm{mM}$ HEPES and $150 \mathrm{mM}$ $\mathrm{NaCl}$ at $\mathrm{pH}$ 7.4. Compounds were injected at a flow rate of $50 \mu \mathrm{L} / \mathrm{min}$ in $10 \mathrm{mM}$ HEPES, $150 \mathrm{mM} \mathrm{NaCl}$, and $0.005 \%$ tween at $\mathrm{pH} 7.4$ for 1 min. Each injection was repeated twice for consistency. Each trace was fit individually to a Langmuir model.

WST-1 Cytotoxicity Assay. HEK293T cells were plated at $1 \times$ $10^{4}$ cells/well in a 96-well plate in DMEM with $10 \%$ fetal bovine serum and $1 \%$ penicillin-streptomycin at $37{ }^{\circ} \mathrm{C}$. After cells were allowed to adhere for $6 \mathrm{~h}$, they were then incubated with the compound for $24 \mathrm{~h}$ in triplicate. A total of $10 \mu \mathrm{L}$ of WST-1 premix (Clontech) was added and incubated for $1 \mathrm{~h}$ followed by measurement using a PerkinElmer EnSpire plate reader. Lines provided are a logistical fit of the data.

Flow Cytometry. HEK293T cells were grown in DMEM with 10\% fetal bovine serum and $1 \%$ penicillin-streptomycin at $37{ }^{\circ} \mathrm{C}$ to $80 \%$ confluency in a 12-well plate and treated with the compound for $24 \mathrm{~h}$. Cells were trypsinized, pelleted, and washed twice with DPBS (Gibco). Cells were then resuspended in $300 \mu \mathrm{L}$ of ice cold DPBS and incubated with $5 \mu \mathrm{L}$ of propidium iodide to stain dead cells. A total of 10000 events were collected using a BD LSR-II flow cytometer.

RNASeq. HEK293T cells were plated in six-well plates and allowed to grow to $80 \%$ confluencey (about 1 million cells), then treated with $0,6.83$, and $20 \mu \mathrm{M} 7$ for $24 \mathrm{~h}$ in triplicate. Cells were then processed according to validated protocols developed by the University of Rochester Genomics Research Center and analyzed for RNAseq (Illumina). Sequenced reads were cleaned according to a rigorous preprocessing workflow (Trimmomatic- $0.32^{63}$ ) before being mapped to the human reference genome (GRCh38.p2) with STAR-2.4.2a. ${ }^{64}$ Cufflinks2.0.2 ${ }^{65}$ with gencode version 23 human gene annotations was then used to perform differential expression analysis with a false discovery rate (FDR) cutoff of 0.05 (95\% confidence interval).

Pseudotyped HIV-1 Infectivity. The antiviral activity of all RNAtargeted compounds was measured by single-round infectivity assay with pseudotyped HIV-1 using HEK293T producer cells. The HIV-1 proviral vector (pDHIV3-GFP) includes all HIV-1 NL4-3 genes except nef (replaced with GFP) and env, thus preserving gag and pol, and the frameshift required for production of the Gag-Pol polyprotein. A single-round infectivity assay was conducted by transient transfection of the viral vector with VSV-G coat protein vector at a ratio of 1:0.5 using Fugene HD (Promega). The virus producer cells were dosed with compounds $4 \mathrm{~h}$ after transfection, and viral particles were harvested from the media $24 \mathrm{~h}$ after transfecting by filtering through a $0.45-\mu \mathrm{m}$ syringe filter. Viral load was normalized with a p24 ELISA (PerkinElmer). The infections were performed using TZM-bl reporter cells containing stably integrated firefly luciferase, the expression of which is driven by the HIV-LTR promoter. Therefore, luciferase is expressed upon successful HIV infection. Triplicate infections in 96well plates at 10000 cells/well with 500 pg p24/well proceeded for 48 $\mathrm{h}$ before the addition of SteadyGlo reagent (Promega) to each well for $30 \mathrm{~min}$. Luminescence was measured as a quantitative metric for changes in viral infectivity in the presence of a compound.
Effect of Compounds on Replication-Competent HIV IIIB. MT-2 cells were obtained from the NIH AIDS Reagent Program and grown in RPMI 1640 media supplemented with $10 \%$ fetal bovine serum. MT-2 cells were seeded in a T-75 cell culture flask at $3 \times 10^{6}$ cells $/ 10 \mathrm{~mL}$ and were infected with $\mathrm{HIV}_{\text {Ішв }}$ at a concentration of 56.5 ng p24/mL. Infection was allowed to proceed for $8 \mathrm{~h}$ in a humidified $37{ }^{\circ} \mathrm{C}$ incubator. Cells were then collected by centrifugation at $250 \mathrm{~g}$ for $5 \mathrm{~min}$. Excess virus was removed, and cells were washed once with dPBS. Cells were then resuspended in fresh growth media and plated in a 48-well culture dish at $1 \times 10^{5}$ cells/well. Compounds were added to cells in triplicate to final concentrations of 20,6 , or $0.6 \mu \mathrm{M}$ such that the total volume was brought to $1 \mathrm{~mL} /$ well. On days 2 and 4 postinfection, $0.5 \mathrm{~mL}$ of supernatant was collected from each well and replaced with $0.5 \mathrm{~mL}$ of fresh media \pm compound of the corresponding concentrations given above. On day 6 postinfection, $0.7 \mathrm{~mL}$ of supernatant was collected, and $30 \mu \mathrm{L}$ of Alamar Blue Cell Viability reagent (ThermoFisher) was added to each well. Alamar Blue fluorescence was measured at ex/em 535/595 with a $30 \mathrm{~nm}$ bandwidth. All supernatant was frozen at $-80{ }^{\circ} \mathrm{C}$ until subsequent analysis of viral load via p24 ELISA according to the manufacturer's instructions (Advanced Bioscience Laboratories). Alamar Blue and ELISA plates were read on a DTX880 Mulitmode Detector (Beckman Coulter).

\section{ASSOCIATED CONTENT}

\section{Supporting Information}

The Supporting Information is available free of charge on the ACS Publications website at DOI: 10.1021/acschembio. 7 b00052.

Characterization of all compounds, surface plasmon resonance data, flow cytometry results, additional fluorescence and Western blot data from pseudotyped HIV experiments, correlation heat map data for RNaseq, and additional $\mathrm{HIV}_{\mathrm{IIIB}}$ inhibition data (PDF)

\section{AUTHOR INFORMATION}

\section{Corresponding Author}

*E-mail: Benjamin_miller@urmc.rochester.edu.

ORCID

Jason R. Myers: 0000-0002-0341-0860

Eric D. Helms: 0000-0003-0072-8889

Benjamin L. Miller: 0000-0001-9168-8047

Notes

The authors declare no competing financial interest.

\section{ACKNOWLEDGMENTS}

We thank Glynis Scott (University of Rochester) for the donation of HEK293T cells and Matt Cochran along with the Flow Core at the University of Rochester for assisting with our flow cytometry experiments. We thank SUNY Geneseo for use of their NMR spectrometer, and Eric Helms for technical assistance. Mass spectrometric analysis by Alice Bergmann in the Chemistry Mass Spectrometry Facility at SUNY at Buffalo is gratefully acknowledged. The following reagesnts were obtained through the NIH AIDS Reagent Program, Division of AIDS, NIAID, NIH: MT-2 Cells from Douglas Richman; HTLV-III $\mathrm{B} / \mathrm{H} 9$ from Robert Gallo; TZM-bl from John C. Kappes, Xiaoyun $\mathrm{Wu}$, and Tranzyme, Inc. This research was supported by the National Institutes of Health through research grant GM100788 (to B.L.M.), Institutional Ruth L. Kirschstein National Research Service Awards GM068411 and AI049815 (T.A.H.), and via the University of Rochester Center for AIDS Research (CFAR), an NIH-funded program (P30 AI078498). 


\section{REFERENCES}

(1) Thomas, J., and Hergenrother, P. (2008) Targeting RNA with Small molecules. Chem. Rev. 108, 1171-1224.

(2) Guan, L., and Disney, M. D. (2012) Recent advances in developing sall molecules targeting RNA. ACS Chem. Biol. 7, 73-86.

(3) Naryshkin, N. A., Weetall, M., Dakka, A., Narasimhan, J., Zhao, X., Feng, Z., Ling, K. K. Y., Karp, G. M., Qi, H., Woll, M. G., Chen, G., Zhang, N., Gabbeta, V., Vazirani, P., Bhattacharyya, A., Furia, B., Risher, N., Sheedy, J., Kong, R., Ma, J., Turpoff, A., Lee, C.-S., Zhang, X., Moon, Y.-C., Trifillis, P., Welch, E. M., Colacino, J. M., Babiak, J., Almstead, N. G., Peltz, S. W., Eng, L. A., Chen, K. S., Mull, J. L., Lynes, M. S., Rubin, L. L., Fontoura, P., Santarelli, L., Haehnke, D., McCarthy, K. D., Schmucki, R., Ebeling, M., Sivaramakrishnan, M., Ko, C.-P., Paushkin, S. V., Ratni, H., Gerlach, I., Ghosh, A., and Metzger, F. (2014) SMN2 splicing modifiers improve motor function and longevity in mice with spinal muscular atrophy. Science 345, 688-693.

(4) Palacino, J., Swalley, S. E., Song, C., Cheung, A. K., Shu, L., Zhang, X., Van Hoosear, M., Shin, Y., Chin, D. N., Keller, C. G., Beibel, M., Renaud, N. A., Smith, T. M., Salcius, M., Shi, X., Hild, M., Servais, R., Jain, M., Deng, L., Bullock, C., McLellan, M., Schuierer, S., Murphy, L., Blommers, M. J. J., Blaustein, C., Berenshteyn, F., Lacoste, A., Thomas, J. R., Roma, G., Michaud, G. A., Tseng, B. S., Porter, J. A., Myer, V. E., Tallarico, J. A., Hamann, L. G., Curtis, D., Fishman, M. C., Dietrich, W. F., Dales, N. A., and Sivasankaran, R. (2015) SMN2 splice modulators enhance U1-pre-mRNA association and rescue SMA mice. Nat. Chem. Biol. 11, 511-517.

(5) Ofori, L. O., Hoskins, J., Nakamori, M., Thornton, C. A., and Miller, B. L. (2012) From Dynamic Combinatorial "Hit" to Lead: In vitro and in vivo activity of compounds targeting the pathogenic RNAs that cause myotonic dystrophy. Nucleic Acids Res. 40, 6380-6390.

(6) Wong, C.-H., Nguyen, L., Peh, J., Luu, L. M., Sanchez, J. S., Richardson, S. L., Tuccinardi, T., Tsoi, H., Chan, W. Y., Chan, H. Y. E., Baranger, A. M., Hergenrother, P. J., and Zimmerman, S. C. (2014) Targeting toxic RNAs that cause myotonic dystrophy type 1 (DM1) with a bisamidinium inhibitor. J. Am. Chem. Soc. 136, 6355-6361.

(7) Coonrod, L. A., Nakamori, M., Wang, W., Carrell, S., Hilton, C. L., Bodner, M. J., Siboni, R. B., Docter, A. G., Haley, M. M., Thornton, C. A., and Berglund, J. A. (2013) Reducing levels of toxic RNA with small molecules. ACS Chem. Biol. 8, 2528-2537.

(8) Childs-Disney, J. L., Parkesh, R, Nakamori, M., Thornton, C. A., and Disney, M. D. (2012) Rational design of bioactive, modularly assembled aminoglycosides targeting the RNA that causes myotonic dystrophy type 1. ACS Chem. Biol. 7, 1984-1993.

(9) Howe, J. A., Wang, H., Fischmann, T. O., Balibar, C. J., Xiao, L., Galgoci, A. M., Malinverni, J. C., Mayhood, T., Villafania, A., Nahvi, A., Murgolo, N., Barbieri, C. M., Mann, P. A., Carr, D., Xia, E., Zuck, P., Riley, D., Painter, R. E., Walker, S. S., Sherborne, B., De Jesus, R., Pan, W., Plotkin, M. A., Wu, J., Rindgen, D., Cummings, J., Garlisi, C. G., Zhang, R., Sheth, P. R., Gill, C. J., Tang, H., and Roemer, T. (2015) Selective small-molecule inhibition of an RNA structural element. Nature 526, 672-677.

(10) Brierley, I., and Dos Ramos, F. J. (2006) Programmed ribosomal frameshifting in HIV1 and the Sars-CoV. Virus Res. 119, 29-42.

(11) Gareiss, P. C., and Miller, B. L. (2009) Ribosomal Frameshifting: An Emerging Target in HIV. Curr. Opin. Invest. Drugs 10, 121-128.

(12) Brakier-Gingras, L., Charbonneau, J., and Miller, B. L. (2014) Drugs targeting the -1 ribosomal frameshifting that generates the enzymes of the human immunodeficiency virus, Frontiers in Clinical Drug Research: HIV, vol 1, pp 67-82, Bentham eBooks, Sharjah, United Arab Emirates.

(13) Belew, A. T., and Dinman, J. D. (2015) Cell cycle control (and more) by programmed -1 ribosomal frameshifting: implications for disease and therapeutics. Cell Cycle 14, 172-178.

(14) Baril, M., Dulude, D., Gendron, K., Lemay, G., and BrakierGingras, L. (2003) Efficiency of a programmed -1 ribosomal frameshift in the different subtypes of the human immunodeficiency virus type 1. RNA 9, 1246-1253.
(15) Mouzakis, K. D., Lang, A. L., Vander Meulen, K. A., Easterday, P. D., and Butcher, S. E. (2013) HIV-1 frameshift efficiency is primarily determined by the stability of base pairs positioned at the mRNA entrance channel of the ribosome. Nucleic Acids Res. 41, 19011913.

(16) Garcia-Miranda, P., Becker, J. T., Benner, B. E., Blume, A., Sherer, N. M., and Butcher, S. E. (2016) Stability of HIV frameshift site RNA correlates with frameshift efficiency and decreased virus infectivity. J. Virol. 90, 6906-6917.

(17) McNaughton, B. R., and Miller, B. L. (2006) Resin-Bound Dynamic Combinatorial Chemistry. Org. Lett. 8, 1803-1806.

(18) McNaughton, B., Gareiss, P., and Miller, B. L. (2007) Identification of a selective small-molecule ligand for HIV-1 frameshift-inducing stem-loop RNA from an 11,325 member resin bound dynamic combinatorial library. J. Am. Chem. Soc. 129, 1130611307.

(19) Meanwell, N. A. (2011) Synopsis of some recent tactical application of bioisosteres in drug design. J. Med. Chem. 54, 25292591.

(20) Palde, P. B., Ofori, L. O., Gareiss, P. C., Lerea, J., and Miller, B. L. (2010) Strategies for Recognition of Stem-loop RNA Structures by Synthetic Ligands: Application to the HIV-1 Frameshift Stimulatory Sequence. J. Med. Chem. 53, 6018-6027.

(21) Ofori, L. O., Hilimire, T. A., Bennett, R. P., Brown, N. W. Smith, H. C., and Miller, B. L. (2014) High-affinity recognition of HIV-1 frameshift-stimulating RNA alters frameshifting in vitro and interferes with HIV-1 infectivity. J. Med. Chem. 57, 723-732.

(22) Hilimire, T. A., Bennett, R. P., Stewart, R. A., Garcia-Miranda, P., Blume, A., Becker, J., Sherer, N., Helms, E. D., Butcher, S. E., Smith, H. C., and Miller, B. L. (2016) N-Methylation as a Strategy for Enhancing the Affinity and Selectivity of RNA-binding Peptides: Application to the HIV-1 Frameshift-Stimulating RNA. ACS Chem. Biol. 11, 88-94.

(23) Gareiss, P. C., Sobczak, K., McNaughton, B. R., Palde, P. B. Thornton, C. A., and Miller, B. L. (2008) Dynamic Combinatorial Selection of Small Molecules Capable of Inhibiting the (CUG) Repeat RNA - MBNL1 Interaction in vitro: Discovery of Lead Compounds Targeting Myotonic Dystrophy (DM1). J. Am. Chem. Soc. 130, 16254-16261.

(24) Ofori, L. O., Hoskins, J., Nakamori, M., Thornton, C. A., and Miller, B. L. (2012) From Dynamic Combinatorial "Hit" to Lead: In vitro and in vivo activity of compounds targeting the pathogenic RNAs that cause myotonic dystrophy. Nucleic Acids Res. 40, 6380-6390.

(25) Low, J. T., Garcia-Miranda, P., Mouzakis, K. D., Gorelick, R. J., Butcher, S. E., and Weeks, K. M. (2014) Structure and dynamics of the HIV-1 frameshift element RNA. Biochemistry 53, 4282-4291.

(26) Rostovtsev, V. V., Green, I. G., Fokin, V. V., and Sharpless, K. B. (2002) A stepwise Huisgen cycloaddition process: copper(I)-catalyzed regioselective "ligation" of azides and terminal alkynes. Angew. Chem., Int. Ed. 41, 2596-2599.

(27) Meldal, M., and Tornoe, C. (2008) Cu-Catalyzed Azide-Alkyne cycloaddition. Chem. Rev. 108, 2952-3015.

(28) Pedersen, D. S., and Abell, A. (2011) 1,2,3-Triazoles in peptidomimetic chemistry. Eur. J. Org. Chem. 2011, 2399-2411.

(29) Angell, Y. L., and Burgess, K. (2007) Peptidomimetics via copper-catalyzed azide-alkyne cycloadditions. Chem. Soc. Rev. 36, $1674-1689$

(30) Luu, L. M., Nguyen, L., Peng, S., Lee, J., Hergenrother, P. J., Chan, H. Y. E., Zimmerman, S. C., Lee, H. Y., and Wong, C.-H. (2016) A potent inhibitor of protein sequestration by expanded triplet (CUG) repeats that shows phenotypic improvements in a Drosophila model of myotonic dystrophy. ChemMedChem 11, 1428-1435.

(31) Ranjan, N., Kumar, S., Watkins, D., Wang, D., Appella, D. H., and Arya, D. P. (2013) Recognition of HIV-TAR RNA using neomycin-benzimidazole conjugates. Bioorg. Med. Chem. Lett. 23, $5689-5693$

(32) Rzuczek, S. G., Park, H., and Disney, M. D. (2014) A toxic RNA catalyzes the in cellulo synthesis of its own inhibitor. Angew. Chem., Int. Ed. 53, 10956-10959. 
(33) Roice, M., Johannsen, I., and Meldal, M. (2004) High capacity poly(ethylene glycol) based amino polymers for peptide and organic synthesis. QSAR Comb. Sci. 23, 662-673.

(34) Sako, Y., Morimoto, J., Murakami, H., and Suga, H. (2008) Ribosomal synthesis of bicyclic peptides via two orthogonal inter-sidechain reactions. J. Am. Chem. Soc. 130, 7232-7234.

(35) Empting, M., Avrutina, O., Meusinger, R., Fabritz, S., Reinwarth, M., Biesalski, M., Voigt, S., Buntkowsky, G., and Kolmar, H. (2011) Triazole bridge": Disulfide-bond replacement by ruthenium-catalyzed formation of 1,5-disubstituted 1,2,3-triazoles. Angew. Chem., Int. Ed. 50, 5207-5211.

(36) Williams, G. M., Lee, K., Li, X., Cooper, G. J. S., and Brimble, M. A. (2015) Replacement of the CysA7-CysB7 disulfide bond with a 1,2,3-triazole linker causes unfolding in insulin glargine. Org. Biomol. Chem. 13, 4059-4063.

(37) Casey, J. P., and Martin, R. B. (1972) Disulfide stereochemistry. Conformations and chiroptical properties of L-cystine derivatives. J. Am. Chem. Soc. 94, 6141-6151.

(38) Tornoe, C., Christensen, C., and Meldal, M. (2002) Peptidotriazoles on solid phase: $[1,2,3]$ - triazoles by regiospecific copper(I) catalyzed 1,3-dipolar cycloadditions of terminal alkynes to azides. J. Org. Chem. 67, 3057-3064.

(39) Nguyen, B., Tanious, F. A., and Wilson, W. D. (2007) Biosensor-surface plasmon resonance: Quantitative analysis of small molecule-nucleic acid interactions. Methods 42, 150-161.

(40) Chatterjee, J., Rechenmacher, F., and Kessler, H. (2013) Nmethylation of peptides and proteins: an important element for modulating biological functions. Angew. Chem., Int. Ed. 52, 254-269.

(41) Buttke, T., McCubrey, J., and Owen, T. (1993) Use of an aqeous soluble tetrazolium/formazan assay to measure viability and proliferation of lymphokine-dependent cell lines. J. Immunol. Methods 157, 233-240.

(42) Heberle, H., Meirelles, G. V., da Silva, F. R., Telles, G. P., and Minghim, R. (2015) InteractiVenn: a web-based tool for the analysis of sets through Venn diagrams. BMC Bioinf. 16, 169.

(43) Platt, E. J. E., Wehrly, K. K., Kuhmann, S. E. S., Chesebro, B. B., and Kabat, D. D. (1998) Effects of CCR5 and CD4 cell surface concentrations on infections by macrophagetropic isolates of human immunodeficiency virus type. J. Virol. 72, 2855-2864.

(44) Derdeyn, C. A., Decker, J. M., Sfakianos, J. N., Wu, X., O’Brien, W. A., Ratner, L., Kappes, J. C., Shaw, G. M., and Hunter, E. (2000) Sensitivity of human immunodeficiency virus type 1 to the fusion inhibitor T-20 is modulated by coreceptor specificity defined by the V3 loop of gp120. J. Virol. 74, 8358-8367.

(45) Notermans, D. W., van Leeuwen, R., and Lange, J. M. (1996) Treatment of HIV infection. Tolerability of commonly used antiretroviral agents. Drug Saf. 15, 176-187. (b) De Clercq, E. (2009) Anti-HIV drugs: 25 compounds approved within 25 years after the discovery of HIV. Int. J. Antimicrob. Agents 33, 307-320.

(46) Popovic, M., Read-Connole, E., and Gallo, R. C. (1984) T4 positive human neoplastic cell lines susceptible to and permissive for HTLV-III. Lancet 324, 1472-1473.

(47) Popovic, M., Sarngadharan, M. G., Read, E., and Gallo, R. C. (1984) Detection, isolation, and continuous production of cytopathic retroviruses (HTLV-III) from patients with AIDS and pre-AIDS. Science 224, 497-500.

(48) Ratner, L., Haseltine, W., Patarca, R., Livak, K. J., Starcich, B., Josephs, S. F., Doran, E. R., Rafalski, J. A., Whitehorn, E. A., Baumeister, K., Ivanoff, L., Petteway, S. R., Jr., Pearson, M. L., Lautenberger, J. A., Papas, T. S., Ghrayeb, J., Chang, N. T., Gallo, R. C., and Wong-Staal, F. (1985) Complete nucleotide sequence of the AIDS virus, HTLV-III. Nature 313, 277-284.

(49) Harada, S., Koyanagi, Y., and Yamamoto, N. (1985) Infection of HTLV-III/LAC in HTLV-I-carrying cells MT-2 and MT-4 and application in a plaque assay. Science $229,563-566$.

(50) Haertle, T., Carrera, C. J., Wasson, D. B., Sowers, L. C., Richman, D. D., and Carson, D. A. (1988) Metabolism and antihuman immunodeficiency virus-1 activity of 2-halo-2', 3'-dideoxyadenosine derivatives. J. Biol. Chem. 263, 5870.
(51) Cummins, N. W., Sainski, A. M., Natesampillai, S., Bren, G. D., and Badley, A. D. (2014) Choice of antiretroviral therapy differentially impacts survival of HIV-infected CD4 T cells. Mol. Cell Ther. 2, 1-7.

(52) Markowitz, M., Mohri, H., Mehandru, S., Shet, A., Berry, L., Kalyanaraman, R., Kim, A., Chung, C., Jean-Pierre, P., Horowitz, A., La Mar, M., Wrin, T., Parkin, N., Poles, M., Petropoulos, C., Mullen, M., Boden, D., and Ho, D. D. (2005) Infection with multidrug resistant, dual tropic HIV-1 and rapid progression to AIDS: a case report. Lancet 365, 1031-1038.

(53) Mohri, H., and Markowitz, M. (2008) In vitro characterization of multidrug-resistant HIV-1 isolates from a recently infected patient associated with dual tropism and rapid disease progression. JAIDS, J. Acquired Immune Defic. Syndr. 48, 511-521.

(54) FY 2017 Trans-NIH Plan for HIV-Related Research. http:// www.oar.nih.gov/strategic_plan/fy2017/OARStrategicPlan2017.pdf.

(55) Dos Ramos, F., Carrasco, M., Doyle, T., and Brierley, I. (2004) Programmed -1 ribosomal frameshifting in the SARS coronavirus. Biochem. Soc. Trans. 32, 1081-1083.

(56) Baranov, P. V., Henderson, C. M., Anderson, C. B., Gesteland, R. F., Atkins, J. F., and Howard, M. T. (2005) Programmed ribosomal frameshifting in decoding the SARS-CoV genome. Virology 332, 498510.

(57) Falk, H., Mador, N., Udi, R., Panet, A., and Honigman, A. (1993) Two cis-acting signals control ribosomal frameshift between human T-cell leukemia virus type II gag and pro genes. J. Virol. 67, 6273-6277.

(58) Advani, V. M., and Dinman, J. D. (2016) Reprogramming the genetic code: the emerging role of ribosomal frameshifting in regulating cellular gene expression. BioEssays 38, 21-26.

(59) Belew, A. T., Meskauskas, A., Musalgaonkar, S., Advani, V. M., Sulima, S. O., Kasprzak, W. K., Shapiro, B. A., and Dinman, J. D. (2014) Ribosomal frameshifting in the CCR5 mRNA is regulated by miRNAs and the NMD pathway. Nature 512, 265-269.

(60) Schmidt, M. W., Baldridge, K. K., Boatz, J. A., Elbert, S. T., Gordon, M. S., Jensen, J. H., Koseki, S., Matsunaga, N., Nguyen, K. A., Su, S. J., Windus, T. L., Dupuis, M., and Montgomery, J. A. (1993) General atomic and molecular electronic structure system. J. Comput. Chem. 14, 1347-1363.

(61) Stephens, P. J., Devlin, F. J., Chabalowski, C. F., and Frisch, M. J. (1994) $A b$ initio calculation of vibrational absorption and circular dichroism spectra using density functional force fields. J. Phys. Chem. 98, 11623-11627.

(62) Miller, S., and Scanlan, T. (1997) Site-selective N-methylation of peptides on solid support. J. Am. Chem. Soc. 119, 2301-2302.

(63) Bolger, A. M., Lohse, M., and Usadel, B. (2014) Trimmomatic: A flexible trimmer for Illumina Sequence Data. Bioinformatics 30, 2114.

(64) GitHub - alexdobin/STAR: RNA-seq aligner. https://github. com/alexdobin/STAR.

(65) Cufflinks. http://cole-trapnell-lab.github.io/cufflinks/. 